\title{
Interactions between marine predators: dolphin food intake is related to number of sharks
}

\author{
Alejandro Acevedo-Gutiérrez* \\ Marine Mammal Research Program, 4700 Avenue U, Building 303, Texas A\&M University at Galveston, Galveston, \\ Texas 77551-5923, USA
}

\begin{abstract}
Dolphins and sharks feed at times on the same food; however, the influence of these interactions on the feeding success of either predator has not been measured. I employed underwater video to record bottlenose dolphins Tursiops truncatus and silky sharks Carcharhinus falciformis feeding on the same school of fish, and for the first time measured food intake of free-ranging dolphins. Regression analyses showed that dolphin food intake diminished as the number of feeding sharks increased, but was unrelated to the number of dolphins feeding, size of the prey clump or duration of feeding events. The number of dolphins increased at the beginning of a feeding event in the presence of sharks but not in their absence. This increase apparently provided a benefit to dolphins since the number of sharks feeding was negatively related to the number of dolphins feeding. Other studies have indicated that risk of shark predation influences dolphin group size and habitat use. This study indicates that interspecific contests over food influence dolphin food intake and perhaps also dolphin group size.
\end{abstract}

KEY WORDS: Feeding ecology · Inter-specific interactions · Food intake $\cdot$ Foraging $\cdot$ Bottlenose dolphins $\cdot$ Silky sharks $\cdot$ Tursiops truncatus $\cdot$ Carcharhinus falciformis

\section{INTRODUCTION}

Group size and composition of predators are influenced by diverse factors such as nature of prey, localization of resources and social interactions (Alexander 1974, Heinsohn \& Packer 1995). Two additional factors thought to influence the group size and the group composition of predators are risk of predation and interspecific contests over food (Alexander 1974, Lima \& Dill 1990, Fanshawe \& Fitzgibbon 1993). Dolphins are marine predators that are preyed upon by certain shark species and this predation pressure may influence dolphin behavior and distribution (Wells et al. 1980, Heithaus 2001). For instance, risk of predation by tiger sharks Galeocerdo cuvieri appears to explain some

${ }^{*}$ Present address: Department of Biology, Western Washington University, 516 High St., Bellingham, Washington 982259160, USA. E-mail: acevedo@biol.wwu.edu of the variability in habitat use, group size and reproductive success of bottlenose dolphins Tursiops aduncus (Mann et al. 2000, Heithaus \& Dill 2002). At the same time, overlaps in diet suggest that dolphins and sharks engage in competitive interactions over food (Heithaus 2001). However, the influence of these interactions on the feeding success of dolphins has not been measured. The presence or absence of hunters from other species influences the feeding success during a kill of terrestrial predators (Waser 1987, Gittleman 1989, Fanshawe \& Fitzgibbon 1993). Thus, other things being equal, one would expect that dolphin feeding success would be affected by the presence or absence of sharks. Here, I present data indicating that the food intake of bottlenose dolphins Tursiops truncatus diminishes as the number of silky sharks Carcharhinus falciformis increases when both species converge on the same food resource, e.g. schooling fish.

Studies in primates and carnivores indicate that a combination of body size and number of individuals 
determines the outcome of interspecific contests over food (Waser 1987, Fanshawe \& Fitzgibbon 1993). In contrast, little is known about this type of interspecific interactions among marine predators due to their relative inaccessibility: they range widely, hunt at depth and occur frequently in murky waters or in the open ocean. However, this study took advantage of a rare opportunity to observe bottlenose dolphins and silky sharks feeding on the same school of fish. The study site has clear waters that make underwater observations feasible and silky sharks are present during $82 \%$ of the observed episodes of dolphin feeding (AcevedoGutiérrez 1997, Acevedo-Gutiérrez \& Parker 2000).

The occurrence in a given area of interactions over food between dolphins and sharks is likely related to factors such as dietary overlap and population abundance. In this regard, the diets of silky sharks and bottlenose dolphins in oceanic waters include similar prey items: squid and epipelagic schooling fish such as scombrids (Compagno 1984, Branstetter 1987, Wells $\&$ Scott 1999). When converging over the same food resource, silky sharks could influence the foraging success of bottlenose dolphins due to their body size and aggregating behavior at food sites (Rey \& MuñozChápuli 1992). Adult silky sharks range from 2.1 to $3.3 \mathrm{~m}$ in length and from 64 to $274 \mathrm{~kg}$ in weight (Garrick et al. 1964, Branstetter 1987), while adult bottlenose dolphins range from 2.0 to $3.8 \mathrm{~m}$ in length and from 110 to $282 \mathrm{~kg}$ in weight (Wells \& Scott 1999). Thus, silky sharks represent a formidable adversary of dolphins when trying to gain access to a food resource.

\section{MATERIALS AND METHODS}

Isla del Coco (center at $05^{\circ} 32^{\prime} \mathrm{N}, 87^{\circ} 04^{\prime} \mathrm{W}$ ) is a small (23 km circumference, $46 \mathrm{~km}^{2}$ area), isolated oceanic island in the eastern tropical Pacific Ocean. It is located approximately $500 \mathrm{~km}$ SW of Costa Rica, beyond the continental shelf.

The methods employed followed those described elsewhere (Acevedo-Gutiérrez \& Parker 2000). I employed a $5 \mathrm{~m}$ inflatable boat to search for dolphins. Each dolphin group sighted was considered a focal group and followed for as long as possible while identifying individual dolphins and recording feeding behavior. Any dolphin within $10 \mathrm{~m}$ (about 2 vessel lengths) of any other dolphin was considered part of the same group. I employed this definition because it was consistent with the number of dolphins feeding around the prey. Individual dolphins were identified from photographs of their dorsal fins (Würsig \& Würsig 1977).

Observations were made from the boat and while snorkeling when dolphins were feeding. Dolphins were judged to be feeding if they were either pursuing fish or holding fish in their mouths (Acevedo-Gutiérrez \& Parker 2000). The amount of time that a focal group spent feeding comprised a feeding event. Due to the difficulty of making prolonged observations underwater when prey and predators are constantly moving, I only analyzed data when prey were clumped near the surface, that is, found in a tight, immobile shoal within the first $10 \mathrm{~m}$ of water (Acevedo-Gutiérrez \& Parker 2000). The 27 sightings averaged (mean \pm SD) $81.4 \pm$ $70.71 \mathrm{~min}$; however, feeding lasted only an average of $23.8 \pm 13.00 \mathrm{~min}$. Feeding groups were considered independent observations because the median number of individuals identified in each group was $71.4 \%$ (interquartile range $=22.22$ to $100 \%$ ) and $89 \%$ of those individuals were sighted just once. The remaining $11 \%$ of individuals were sighted twice, with a long time between resightings (median $=36.5 \mathrm{~d}$, interquartile range $=8$ to $63.3 \mathrm{~d}$ ).

To estimate food intake of dolphins, feeding events were recorded on underwater video. From the footage, I estimated the number of dolphins and the number of sharks feeding on the clump as well as the number of times that dolphins swam towards the ball of prey and captured a prey item. Food intake was defined as the number of captures of prey by dolphins $\mathrm{min}^{-1}$, where 1 capture equals 1 fish. Because I was unable to detect a focal dolphin continuously, I divided the total number of captures by the number of dolphins feeding. Thus, food intake values represent an average and their units are fish dolphin ${ }^{-1} \mathrm{~min}^{-1}$. I was able to detect all captures made by dolphins because the size of the clumps of prey was relatively small (range $=4$ to $18 \mathrm{~m}^{3}$ ) and the dolphins captured fish one at a time. The clump of prey was constituted by a single fish species, which varied with feeding event but always consisted of epipelagic schooling fish: Carangoides orthogrammus, Sarda sp., Auxis sp. or Fodiator sp. Opportunistic captures and comparisons to dolphin body size, using a dolphin length of $2.5 \mathrm{~m}$ as reference, indicated that the prey was approximately 20 to $30 \mathrm{~cm}$ in length.

Fourteen events were recorded on video an average time of $3.1 \pm 2.91 \mathrm{~min}$, sharks were present in 9 and absent in 5 of these events. I employed multiple linear regression to relate food intake $\mathrm{min}^{-1}$ dolphin $^{-1}$ to number of dolphins feeding, number of sharks feeding, relative size of the clump of prey and duration of feeding events. The size of the clump of prey relative to the length of dolphins was visually estimated from the video footage. The independent variables were log transformed before conducting the multiple regression analysis. There was mild multicolinearity in the multiple regression analysis because the independent variables number of sharks and number of dolphins were correlated. Although the multicolinearity was not large enough to significantly alter the results, I also per- 
formed an analysis to discard unnecessary independent variables, reduce the standard errors of $b$ (where $b=$ regression coefficient) and obtain the best regression model based on high correlation coefficients and low square errors, specifically the square root of the mean square error and Mallow's Cp (Hintze 2001).

I compared the number of dolphins before feeding and during feeding in the presence and absence of sharks using a Wilcoxon paired-sample test. Eighteen events were included in the analysis because group size before feeding could not be estimated for 9 events. The number of dolphins was recorded when they were at the surface (about every 3 to $5 \mathrm{~min}$ ) or every $3 \mathrm{~min}$ if

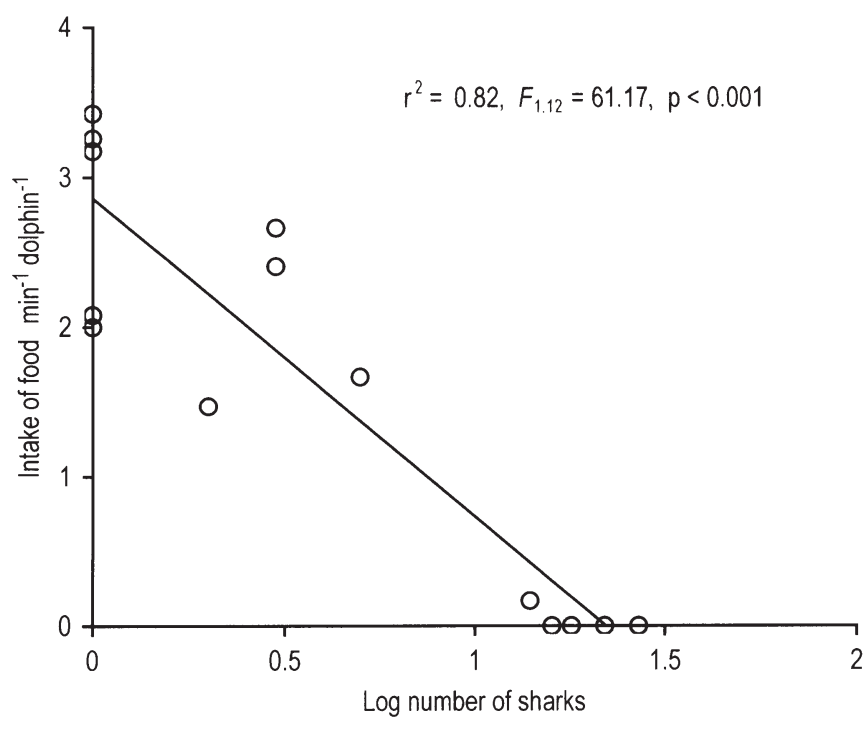

Fig. 1. Dolphin food intake relative to the number of sharks feeding. See statistical results in Table 1 they were continuously at the surface, each of these records represented a bout. Because group size was consistent between bouts, I employed the median value of bouts as the number of dolphins in the focal group.

\section{RESULTS AND DISCUSSION}

Dolphin food intake diminished as the number of sharks feeding increased; according to the multiple regression analysis, none of the other variables analyzed-number of dolphins feeding, size of the clump of prey or duration of feeding events - had a significant effect on dolphin food intake (Table 1). The best regression analysis yielded similar results by only including the number of sharks feeding as the independent variable in the model (Fig. 1, Table 1). Silky sharks and dolphins fed on the same clumped prey; however, only 1 species entered the clump at a time. In 3 events, dolphins chased sharks away from the ball of prey. When sharks were feeding, they stayed inside the clump while dolphins remained on the periphery, feeding sporadically on prey darting from the clump (Fig. 2). Dolphins resumed feeding after sharks moved out of the clump. Based on their size relative to the observer underwater $(1.9 \mathrm{~m})$, both sharks and dolphins measured approximately $2.5 \mathrm{~m}$.

The question arising as to why did dolphins not feed when sharks were also feeding? Dolphins were perhaps preventing the break-up of clumps of prey, which would also explain why I only observed dolphins feeding one at a time, a behavior also observed in other dolphin species (Würsig 1986, Fertl \& Würsig 1995). Another possibility is that dolphins were avoiding acci-

Table 1. Dolphin food intake in relation to number of dolphins, number of sharks, size or prey clump and duration of feeding events. $b$ : regression coefficient; $t$ : Student $t$ statistic; SR: square root; MSE: mean standard error

\begin{tabular}{|c|c|c|c|c|c|}
\hline Variable & $b$ & $\mathrm{SE}$ of $b$ & $t$ & $\mathrm{p}$ & Regression \\
\hline \multicolumn{6}{|l|}{ Multiple linear regression } \\
\hline Constant & 3.785 & 1.659 & 2.282 & 0.048 & $r^{2}=0.83$ \\
\hline Log of number of feeding dolphins & -1.487 & 0.771 & -1.929 & 0.086 & $\begin{array}{l}F_{4,9}=17.37 \\
p<0.001\end{array}$ \\
\hline Log of number of feeding sharks & -2.639 & 0.375 & -7.044 & $<0.001$ & $\mathrm{SR}$ of $\mathrm{MSE}=0.542$ \\
\hline Log of size of prey clump & 0.260 & 0.947 & 0.275 & 0.790 & Mallow's Cp $=5.00$ \\
\hline Log of duration of feeding event & 0.345 & 0.693 & 0.498 & 0.630 & \\
\hline \multicolumn{6}{|l|}{ Best regression model. See Fig. 1} \\
\hline Constant & 2.859 & 0.221 & 12.961 & $<0.001$ & $\mathrm{r}^{2}=0.82$ \\
\hline Log of number of feeding sharks & -2.126 & 0.272 & -7.821 & $<0.001$ & $\begin{array}{l}F_{1,12}=61.17 \\
\mathrm{p}<0.001 \\
\text { SR of MSE }=0.561 \\
\text { Mallow's } \mathrm{Cp}=2.87\end{array}$ \\
\hline
\end{tabular}




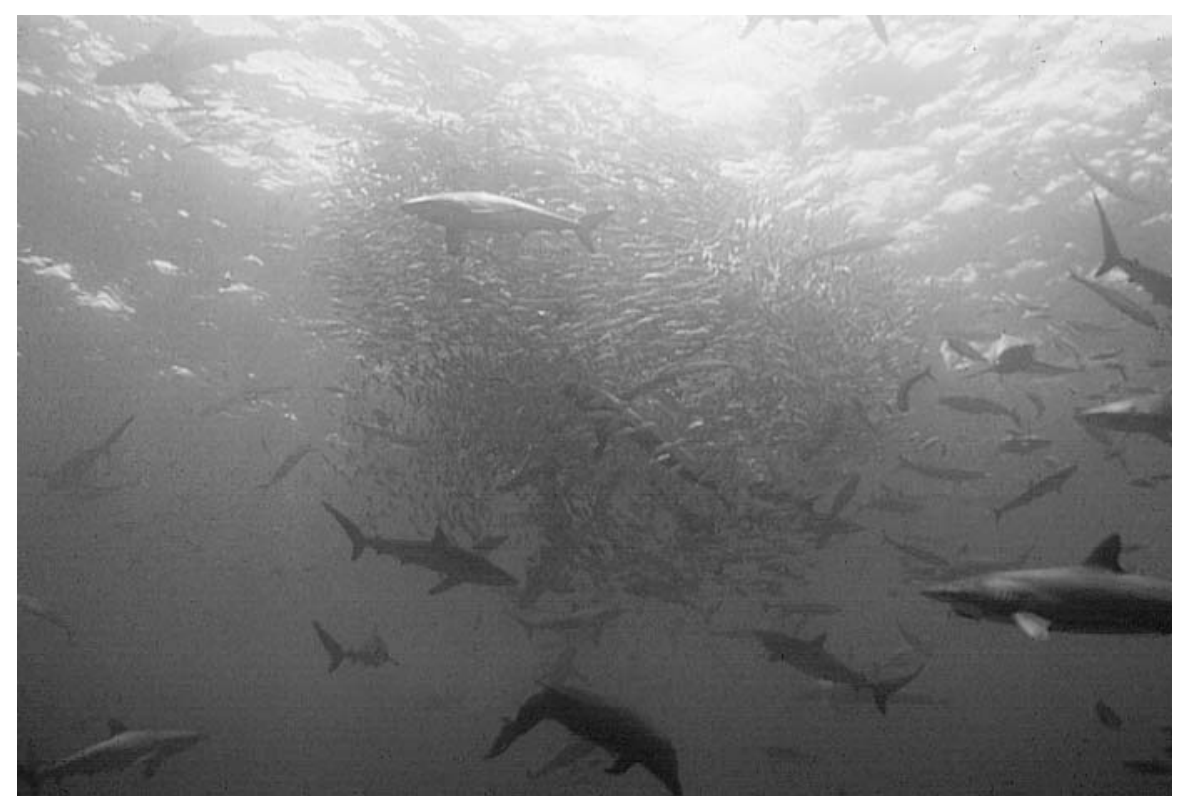

Fig. 2. Sharks and dolphins feeding on epipelagic schooling fish. More sharks than dolphins were observed in this particular event (a dolphin can be seen at the center of the bottom edge of the picture). Photo by J. Ireland and G. Bradley
$\mathrm{r}_{\mathrm{S}}=-0.63, \mathrm{n}=14$ events, $\mathrm{p}=$ 0.015). Although I could not measure shark food intake, the previous results suggest that sharks had a higher food intake when dolphins were found in small groups. I observed dolphins chasing sharks away from the clump of prey as dolphin group size increased, suggesting that dolphins caused the reduction in shark numbers; however, conclusive evidence is needed. These chases occurred on limited occasions, as the interactions between the 2 predators appeared to be subtle. The paucity of aggressive interactions between dolphins and sharks is not surprising given that constant clashing may be costly, particularly when both species meet frequently (Heithaus 2001).

dental wounds from sharks. When sharks were feeding, they slashed back and forth inside the clump of prey for several seconds. Any animal or object in the vicinity would have been struck.

The number of sharks feeding was negatively related to dolphin group size (Spearman rank correlation: $\mathrm{r}_{\mathrm{S}}=$ $-0.67, \mathrm{n}=14$ events, $\mathrm{p}=0.008$; Fig. 3). Likewise, the time that sharks fed also had a negative relationship with the number of dolphins (Spearman rank correlation:

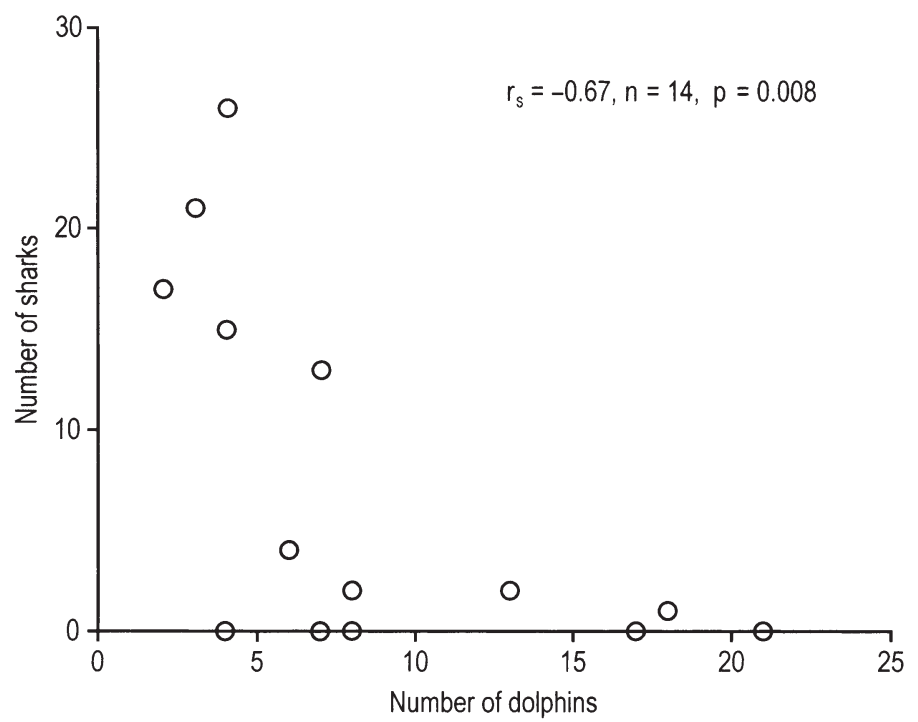

Fig. 3. Number of sharks and number of dolphins feeding

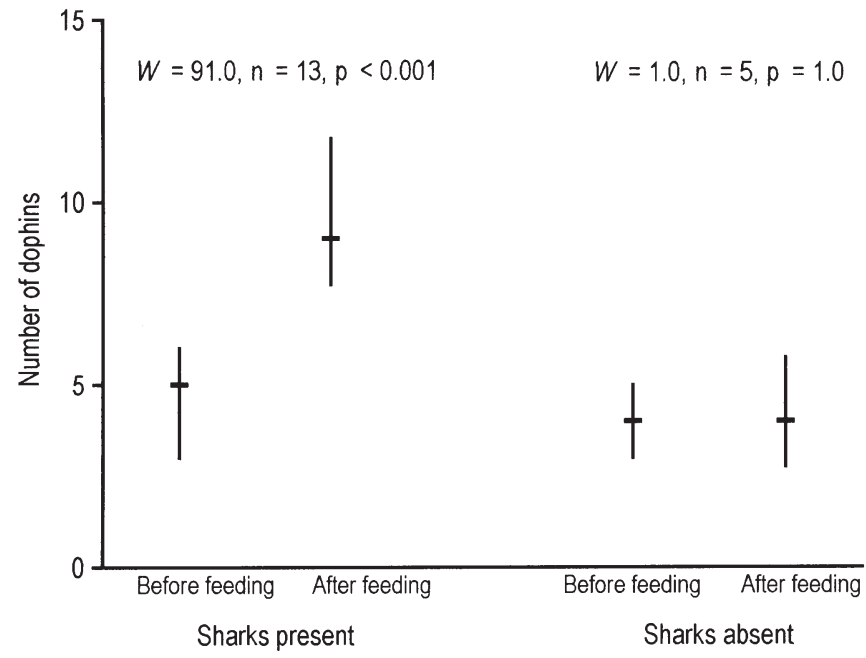

Fig. 4. Changes in number of dolphins feeding relative to shark presence or absence. Vertical lines: interquartile range; horizontal bars: median 
ing (Wilcoxon paired-sample test: $W=1.000, \mathrm{n}=5, \mathrm{p}=$ 1.000). Thus, the data suggest that dolphin group size was regulated according to presence or absence of sharks. Yet, it is not possible to reach any conclusive statements because the sample size for changes in dolphin group size in the absence of sharks was small. In addition, it was unclear whether dolphins fed as a group or merely aggregated to a food resource, a distinction that is rather difficult to establish (Janik 2000).

Silky sharks feed on a variety of fish and squid (Compagno 1984, Branstetter 1987) and are not considered a predator of dolphins (Heithaus 2001). I never observed silky sharks attacking a dolphin, and young dolphins were seen at times without any adult in sight during feeding events. Dolphins never appeared to be agitated in the presence of sharks. Thus, the interactions reported here appeared to represent interspecific contests over food and not interactions between predator and prey.

The data indicate that dolphin food intake was negatively related to the number of sharks feeding. They also suggest that increases in dolphin group size prevented sharks from aggregating around the clump of prey. Future studies might describe the relationship between dolphin group size and shark food intake, and determine if dolphins manipulate their numbers at feeding events according to shark presence or absence.

Acknowledgements. I am grateful to K. Dudzik and Y. Camacho for assistance in the field. B. Würsig introduced me to Isla del Coco. The Area de Conservación Marina Isla del Coco, Okeanos Aggressor and Undersea Hunter provided logistic support. G. Bradley and J. Ireland made available footage and pictures of feeding events. W. Neill, J. Packard, F. Schlemmer II, D. Weller and B. Würsig reviewed earlier drafts of this manuscript. I thank R. Baird, D. Costa, D. Croll, J. Donlan, D. Kort, P. Levin, B. Tershy, T. Williams and anonymous reviewers for their comments. Funding was provided by the Marine Mammal Research Program, Texas A\&M University at Galveston, Earthwatch-Center for Field Research and The Netherlands Embassy in Costa Rica, and by fellowships from Texas A\&M University, International Women's Fishing Association and Houston Underwater Society.

\section{LITERATURE CITED}

Acevedo-Gutiérrez A (1997) Group feeding in bottlenose dolphins at Isla del Coco, Costa Rica: inter-specific interactions with prey and other hunters. PhD thesis, Texas A\&M University, College Station

Acevedo-Gutiérrez A, Parker N (2000) Surface behavior of bottlenose dolphins is related to spatial arrangement of prey. Mar Mamm Sci 16:287-298

Alexander RD (1974) The evolution of social behavior. Annu Rev Ecol Syst 5:325-383

Editorial responsibility: Otto Kinne (Editor), Oldendorf/Luhe, Germany
Branstetter S (1987) Age, growth and reproductive biology of the silky shark, Carcharhinus falciformis, and the scalloped hammerhead, Sphyrna lewini, from the northwestern Gulf of Mexico. Environ Biol Fishes 19:161-173

Compagno LMV (1984) Sharks of the world. Part 2, Carcharhiniformes. FAO Fish Synop No. 125 4(2):251-655

Fanshawe JH, Fitzgibbon CD (1993) Factors influencing the hunting success of an African wild dog pack. Anim Behav 45:479-490

Fertl D, Würsig B (1995) Coordinated feeding by Atlantic spotted dolphins (Stenella frontalis) in the Gulf of Mexico. Aquat Mamm 21:3-5

Garrick JAF, Backus RH, Gibbs RH Jr (1964) Carcharhinus floridianus, the silky shark, a synonym of C. falciformis. Copeia 1964:369-375

Gittleman JL (1989) Carnivore group living: comparative trends. In: Gittleman JL (ed) Carnivore behavior, ecology, and evolution. Cornell University Press, Ithaca, p 183-207

Heinsohn R, Packer C (1995) Complex cooperative strategies in group-territorial African lions. Science 269: $1260-1262$

Heithaus MR (2001) Predator-prey and competitive interactions between sharks (order Selachii) and dolphins (suborder Odontoceti): a review. J Zool 253:53-68

Heithaus MR, Dill LM (2002) Food availability and tiger shark predation risk influence bottlenose dolphin habitat use. Ecology 83:480-491

Hintze J (2001) NCSS and PASS. Number cruncher statistical systems. NCSS Statistical Software, Kaysville, UT

Janik VM (2000) Food-related bray calls in wild bottlenose dolphins (Tursiops truncatus). Proc R Soc Lond Ser B 267: 923-927

Lima SL, Dill LM (1990) Behavioral decisions made under the risk of predation: a review and prospectus. Can J Zool 68: 619-640

Mann JM, Connor RC, Barre LM, Heithaus MR (2000) Female reproductive success in bottlenose dolphins (Tursiops sp.): life history, habitat, provisioning, and group size effects. Behav Ecol 11:210-219

Rey JC, Muñoz-Chápuli R (1992) Intra and interspecific association of large pelagic fishes inferred from catch data of surface longline. Environ Biol Fishes 35:95-103

Waser P (1987) Interactions among primate species. In: Smuts BB, Cheney DL, Seyfarth RM, Wrangham RW, Struhsaker TT (eds) Primate societies. University of Chicago Press, Chicago, p 210-226

Wells RS, Scott MD (1999) Bottlenose dolphin Tursios truncatus (Montagu, 1821). In: Ridgway SH, Harrison R (eds) Handbook of marine mammals, Vol 6. Academic Press, San Diego, p 137-182

Wells RS, Irvine AB, Scott MD (1980) The social ecology of inshore odontocetes. In: Herman LM (ed) Cetacean behavior: mechanisms and functions. Wiley-Liss, New York, p 263-318

Würsig B (1986) Delphinid foraging strategies. In: Schusterman RJ, Thomas JA, Wood FG (eds) Dolphin cognition and behavior: a comparative approach. Erlbaum, Hillsdale, p 347-359

Würsig B, Würsig M (1977) The photographic determination of group size, composition, and stability of coastal porpoises (Tursiops truncatus). Science 198:755-756

Submitted: February 20, 2002; Accepted: May 7, 2002

Proofs received from author(s): August 7, 2002 